\title{
Research on Methods of Improving Employee's Sense of Happiness
}

\author{
Jia $\mathrm{He}^{1, *}$ \\ ${ }^{1}$ Beijing 21st century international school, Beijing, China, 100037 \\ *Corresponding author. Email: 13051662541@163.com
}

\begin{abstract}
In the last century, the rapid development of psychology has made it possible to move beyond individual therapy and counseling applications to scientific analysis and research for companies. Scholars have attempted to integrate theory into practical work to guide companies in a rational and scientific manner, and have now found that employee productivity and their well-being are inextricably linked. In this paper, by reviewing the past literature, we summarize the factors that affect employee happiness and give details of some ways to help the development of enterprises, the specific influencing factors can be divided into rest time and mental satisfaction. The conclusion is that the helping employees to balance between job and life, trusting employees, appreciating employees, showing bright job prospects to employees and hiring an IO psychologist are methods of improving employee's sense of happiness.
\end{abstract}

Keywords: workers, enterprise, happiness, IO psychology, employer

\section{INTRODUCTION}

Since companies have to get their work done through people, the mindset and efficiency of employees will influence any kind of change, affecting the improvement of projects and even the development of the whole company. Employees who are happy at work are more likely to stay there. The stress of finding and training new employees would be reduced if turnover was lower. A research conducted by Oxford University's Sad Business School at a British telecommunications corporation discovered that cheerful employees were 13 percent more productive. [10] Over the course of several weeks, the study followed 1,800 workers and their own feelings of happiness. Gallup found that 85 percent of the world's one billion full-time workers are dissatisfied with their jobs, according to a global poll. [10] Most of the company's employees lose their sense of life experience due to a decrease in happiness. This in turn leads to increased company turnover and decreased production due to lack of well-being. The specific influencing factors can be divided into time off and mental satisfaction, and this literature discusses the purpose of creating a more rational work environment that allows society to operate more efficiently, develop virtuously, and help companies profit through contagious happiness. This article lists five ways to improve employee happiness, which are balancing between job and life, appreciation, trust, bright job prospects and hiring an IO psychologist. Increasing happiness is of great benefit to both employees and employers. This is because the employee's situation has a direct impact on the company's progress.

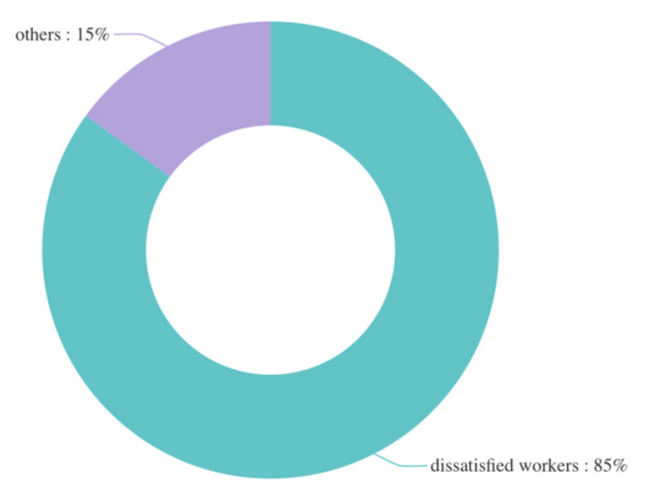

Figure 1 the world's one billion full-time workers

\section{ANALYSIS OF THE WAYS OF IMPROVE EMPLOYEES' HAPPINESS}

\section{1 balance between job and life}

First, not everyone strives for the same work-life 
balance. It's critical to discuss each employee's goals and identify what employers can do to assist them in achieving them. Some employees may benefit from working remotely for a number of days each week, while others may opt to change their regular work schedule. Employers should be open-minded and adaptable. For example, some people are most efficient at midnight or the beginning of a day. People have their own g working time.

Second, employees would follow employer's lead. People's minds would change based on the habits and fashion of their friends or surroundings. for example, if the leaders are sending emails at all hours of the day and night or working hard on the weekends, his/her staff is going to think that is what is expected of them too. This is a way for workers to persuade themselves on the mental level.

Third, providing more break time. "When employees are able to take a true break from work without feeling uneasy about it, they return more refreshed and engaged," says the author. "Performance improves when employees are given time and space to focus on personal relationships and non-work-related pastimes that bring them delight," said Shelley Osborne, head of learning and development at Udemy. [8] Employees should value the time they have to decompress, even if they have periods where they need to work longer hours and pay more attention.

Forth, helping workers to solve their family problems is a way to improve their balance between life and work. Few people strive more than mothers to strike the ideal work-life balance. Their job expectations are higher than ever: according to new study, nearly $40 \%$ of working mothers are the sole breadwinners for their families. [7] A quarter of the working women polled believe they have to choose between their children and their careers, and almost as many say work responsibilities have pushed them to do so. Moreover, many companies have already provided some welfares like Childcare discount or household settlement.

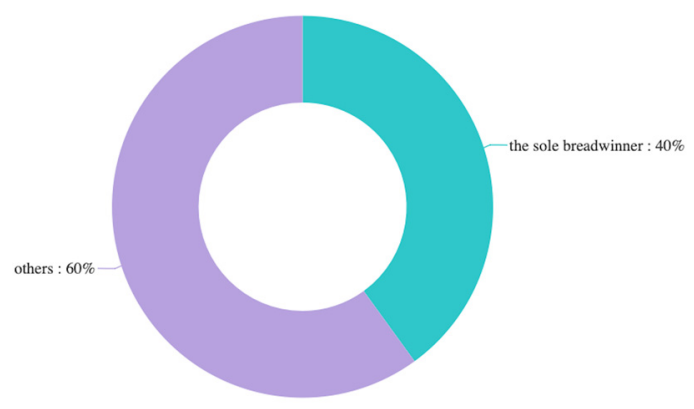

Figure 2 working mothers

\subsection{Trust}

According to a PayScale survey, the happier employees are and the less likely they are to look for a new job, the more their managers trust them. The research was based on the responses of 54,827 employees in the United States. According to the study, 72 percent of workers who can act and make decisions on their own are content with their careers. Only $26 \%$ of employees who are unable to accomplish anything without first being instructed are equally satisfied. [6] Human nature has its common characteristic, which is the desire to make oneself an important person, recognized and valued by the organization. Based on this, trusting employees in management and making them feel that they are valued by their leaders at all times is certainly an incentive and motivation for employees. Ways to increase the trust of employees and employers: 1. fair pay and promotion opportunities 2 . strong leadership 3. low turnover 4. a collaborative work environment 5 . consistency 6 . verbal recognition

\section{3 appreciation}

According to Tanner Learning Group, 79 percent of those who quit their jobs did so because they didn't feel valued. [15] Leadership that is closed to subordinates' ideas or dismissive of team members undermines motivation and happiness. According to the same Tanner study, 94 percent of employees who reported strong work morale stated their superiors were adept at rewarding them. Businesses that do not respect a person's basic human rights, such as a proper bathroom break or vital safety equipment, see a drop in productivity. All of this has an impact on employee morale, causing them to become dissatisfied and hunt for new options.

Employee ideas should be heard, and the leader should make sure that this is possible. Examine the employee grievance procedure to ensure that concerns are handled with respect and in accordance with standard human resource practices. Austrian psychiatrist and Holocaust survivor Victor Frankl showed that human beings are motivated by a "will to mean". [11] When we live with meaning and purpose, we thrive. When we lack meaning, we may struggle or become frustrated. Employee efforts must be recognized by the team's leadership. People desire to be recognized and appreciated for their efforts. In this fast-paced life, if someone can take the time to notice and value an employee, perhaps by sharing a news, they feel good about being valued in their work environment, so the employee thrives on positive feedback from others, and this feeling of being valued and appreciated enhances the employee's positive sense of self-worth. As if when a supervisor expresses appreciation for an employee's results and reports, it reminds the employee 
that what they are doing is meaningful. Influencing employees in this small way will add meaning to their lives. Complimenting others will in turn be recognized by them. Because when others feel your liking, they will think that you share the same values and aesthetics as them, and in turn will see you as a friend and give them trust and recognition. However, you need to pay attention to the main points when complimenting, you should not overdo it. The frequency should not be too fast either. Over-complimenting can make others think the complimenter is very hypocritical. Employees may also become overly arrogant and lose sight of their original strengths. Too often can lead to a habit of always wanting to be recognized. When an employee accomplishes something more meaningful than what he was previously complimented on, but does not receive feedback, he may develop a complaining and frustrated mindset. In addition, leaders can show their recognition by giving some physical rewards. Offering staffs rewards encourages them to work hard and progress, just as an incentive could motivate people. People prefer to be appreciated and rewarded for their efforts, and incentives are one method to demonstrate that hard work pays off. Employee incentive programs that include things like gift cards, additional time off, and free lunch are not only wonderful for staffs; they're also good for business in the long run. During an incentive period, 73 percent of employees described the office atmosphere as "good" or "very good," according to a 2018 study by Genesis Associates. [9] Members of a team who feel respected and valued at work are intrinsically more productive. Their capacity to express themselves means they're more inclined to bounce ideas off one another, which boosts creativity. They are more focused and motivated to complete projects when they feel valued and like they are making a difference.

\subsection{Bright Job Prospects}

Maria Kraimer, a business professor at the University of Iowa, found that providing development support, such as training opportunities and career coaching, to employees who do not believe that there are career opportunities within the company that is attractive to them can lead to such employees leaving the organization. It is critical that companies have regular career planning discussions with their employees. [1]

Contemporary society is evolving rapidly and the cycle of knowledge renewal is becoming shorter and shorter. Because of peer pressure as well as career demands, the need for people to develop themselves is becoming stronger. Start by promoting learning and development opportunities for everyone. No one likes to feel stuck in a dead-end job with no opportunities for advancement. Let everyone see the path to growth. As a result, employees will demand more training for themselves, as well as upgrading their self-skills. Everyone wants to improve and be motivated, and employees are no exception, they always expect and consider whether the company can provide them with more learning opportunities and room for advancement.

They always expect and consider whether the company can provide them with more learning opportunities and room for advancement, so that they can work hard to achieve better positions and higher salaries in the future. Everyone plans their own life, and employees will be very happy when they find themselves in a company with a good future, and the company needs to share its progress and future plans with employees to suggest that their efforts are not in vain such as presenting companies' achievement in this year. Leaders should keep employees engaged with the brand. Make sure the company has a clear and unified goal. Communicate this vision to everyone so that they feel part of a team working to achieve the goal. When employees have a common goal, they will work with each other openly, reducing communication costs and barriers, enhancing task completion rates and happy relationships.

\subsection{Hire an IO psychologists}

If leaders have a large global organization and want to develop ongoing training programs and conduct long-term research on workplace culture across multiple locations, then an in-house psychologist would be a good choice. They can help medium to large companies improve employee satisfaction productivity and happiness. [2] These professionals are valuable assets. Its research findings and principles have a strong connection with every employee, and it aids in the discovery of useful and efficient organizational strategies. IO psychologists are frequently enlisted to assist businesses in acquiring a more productive and healthier workforce. Conversely, if the leader owns a small business, then they can go and ask IO psychologist consultants. And can give employees a personality assessment to work with the team based on individual preferences work style and behavior.

\section{CONCLUSION}

85 percent of the world's one billion full-time workers are dissatisfied with their jobs. [10] Every day is a muddle to find your meaning. Increasing happiness is of great benefit to both employees and employers. The five methods to improve employees' happiness mentioned in this article and give solutions. Again, here is the summary: Method 1: To balance life and work. First, employers can set work schedules that vary from person to person; Second, employers can set an example; Third, employers can provide more breaks for employees; Fourth, employers can help employees 
solve their life problems. Method two: Giving trust. There are three specific measures. Method three: Showing appreciation. Specific measures are verbal moderate praise and in-kind rewards. Method four: Providing bright job prospects. Specific measures are to provide employees with more training to enhance their skills and to communicate the company's recent progress and future development direction. Method 5: Hiring industrial psychologists to improve employee happiness for different company situations and environments. The above methods can be used in combination for better results.

\section{ACKNOWLEDGMENTS}

In the end, thanks to the guidance of my thesis teacher.

\section{REFERENCES}

[1]Businessnewsdaily.com. 2021. [online] Available at: $<$ https://www.businessnewsdaily.com/6084-emplo yee-happiness-without-raise.html $>$ [Accessed 14 August 2021].

[2]Businessnewsdaily.com. 2021. [online] Available at: $<$ https://www.businessnewsdaily.com/10162-indus trial-organizational-psychology.html $>$ [Accessed 14 August 2021].

[3]Businessnewsdaily.com. 2021. [online] Available at: $<$ https://www.businessnewsdaily.com/8108-work-1 ife-balance-quiz.html $>$ [Accessed 14 August 2021].

[4]Businessnewsdaily.com. 2021. [online] Available at: $<$ https:/www.businessnewsdaily.com/5244-impro ve-work-life-balance-today.html> [Accessed 14 August 2021].

[5]Businessnewsdaily.com. 2021. [online] Available at: $<$ https://www.businessnewsdaily.com/7712-work-1 ife-balance-home-entrepreneurs.html $>$ [Accessed 14 August 2021].

[6]Businessnewsdaily.com. 2021. [online] Available at: $<$ https://www.businessnewsdaily.com/9507-emplo yee-trust-benefits.html $>$ [Accessed 15 August 2021].

[7]Businessnewsdaily.com. 2021. [online] Available at: $<$ https://www.businessnewsdaily.com/2511-work-1 ife-balance-tips.html> [Accessed 15 August 2021].

[8]Businessnewsdaily.com. 2021. [online] Available at: $<$ https://www.businessnewsdaily.com/10208-week end-work-life-balance.html $>$ [Accessed 15 August 2021].

[9]Businessnewsdaily.com. 2021. [online] Available at: $<$ https://www.businessnewsdaily.com/8506-emplo yee-productivity-incentives.html $>$ [Accessed 15 August 2021].

[10]Gallup, I., 2021. The World's Broken Workplace. [online] Gallup.com. Available at: $<$ https://news.gallup.com/opinion/chairman/21204 5/world-broken-workplace.aspx?g_source=positio n1\&g_medium $=$ related\&g_campaign $=$ tiles $>$ [Accessed 14 August 2021].

[11]Encyclopedia Britannica. 2021. Viktor Frankl Biography, Books, Theory, \& Facts. [online] Available at: $<$ https://www.britannica.com/biography/Viktor-Fr ankl $>$ [Accessed 15 August 2021].

[12]Psychology Today. 2021. Why We Like Being Appreciated. [online] Available at: $<$ https:/www.psychologytoday.com/us/blog/intim acy-path-toward-spirituality/201604/why-we-being -appreciated $>$ [Accessed 14 August 2021].

[13]Zhihu.com. 2021. Trust is not only the best way to motivate employees but also the highest level. [online] Available at: $<$ https://zhuanlan.zhihu.com/p/370221032?utm_so urce $=$ wechat_session\&utm_medium $=$ social\&utm oi $=949326171670843392 \& u t m \_$campaign $=$shareo pn> [Accessed 14 August 2021].

[14]Zhihu.com. 2021. How do I show the new employees the company's future? - Zhihu. [online] Available at: $<$ https://www.zhihu.com/question/440661204/ans wer/1692334696> [Accessed 14 August 2021].

[15]Zhihu.com. 2021. How important is mutual trust among team members to the execution of the team? - Zhihu. [online] Available at: $<$ https://www.zhihu.com/question/19593705> [Accessed 14 August 2021].

[16]Zhihu.com. 2021. How to enhance team cohesion and compliment employees? - Zhihu. [online] Available at: $<$ https:/www.zhihu.com/question/56820523/answ er/713576549?utm_source $=$ wechat_session\&utm medium $=$ social\&utm_oi $=949326171670843392 \&$ utm_content=group3_Answer\&utm_campaign $=$ sh areopn $>$ [Accessed 14 August 2021]. 